Journal of Southeast Asian

\title{
Behind the Curtain: The Cultural Capital of Pilipino Cultural Nights
}

Xavier J. Hernandez

Purdue University, xhernand@gmail.com

Follow this and additional works at: https://docs.lib.purdue.edu/jsaaea

Part of the Asian American Studies Commons, and the Higher Education Commons

\section{Recommended Citation}

Hernandez, Xavier J. (2020) "Behind the Curtain: The Cultural Capital of Pilipino Cultural Nights," Journal of Southeast Asian American Education and Advancement: Vol. 15 : Iss. 1, Article 1.

DOI: $10.7771 / 2153-8999.1165$

Available at: https://docs.lib.purdue.edu/jsaaea/vol15/iss1/1

This document has been made available through Purdue e-Pubs, a service of the Purdue University Libraries. Please contact epubs@purdue.edu for additional information.

This is an Open Access journal. This means that it uses a funding model that does not charge readers or their institutions for access. Readers may freely read, download, copy, distribute, print, search, or link to the full texts of articles. This journal is covered under the CC BY-NC-ND license. 


\section{Behind the Curtain: The Cultural Capital of Pilipino Cultural Nights}

\section{Cover Page Footnote}

This work is dedicated to my lola, Constantina Osorio, who put the clothes on my back so that I could step out on that stage. I am also eternally grateful the Pilipinos Sharing Smiles Together Family, who changed my life forever by cultivating my love for PCN at a time when I needed it the most. Lastly, words cannot express my gratitude to the members of Kababayan, the Philippine Student Association, and the Purdue Filipino Association, who helped me find my calling as a community member and a scholar. 


\title{
JSAAEA Journal of Southeast Asian American
Education and Advancement
}

Vol. 15 Iss. 1 (2020)

WWW.JSAAEA.org

\section{Behind the Curtain: The Cultural Capital of Pilipino Cultural Nights}

\author{
Xavier J. Hernandez \\ University of California Irvine
}

\begin{abstract}
This study examines the phenomenon of Pilipino Cultural Nights in higher education through the lens of community cultural wealth. While in name, Pilipino Cultural Nights pay homage to the native culture of the Philippines, the processes through which these performances are produced and reproduced as annual traditions exhibit a distinct Filipino American cultural experience that is facilitated by the higher education environment. As under-represented and under-served students, Filipino American students utilize their various forms of community cultural wealth to create one of the most visible performances on their campus and a cornerstone coming of age experience for Filipino American youth. But as the Pilipino Cultural Night has become larger and more institutionalized, students must deal with the shifting scales of value for various forms of community cultural wealth. The balance that these students attempt to strike between the short- and long-term goals of the production, its intrinsic and extrinsic value, and the Filipino and Filipino American traditions that it celebrates, reflect the dynamic process of culture that goes far beyond the stage. Through exploring these struggles, diversity and inclusion efforts on college campuses can gain a holistic understanding of how to serve emerging student populations who seek more than mere representation.
\end{abstract}

Keywords: Higher education, Diversity, Student organizations, Performing arts, Filipino American

\footnotetext{
(c)

SDRERIIGHISRESERNEDR Readers are free to copy, display, and distribute this article, as long as the work is attributed to the author(s) and the Journal of Southeast Asian American Education \& Advancement, it is distributed for non-commercial purposes only, and no alteration or transformation is made in the work. More details of this Creative Commons license are available at http://creativecommons.org/licenses/by-nc-nd/3.0/. All other uses must be approved by the author(s) or JSAAEA.

Journal of Southeast Asian American Education \& Advancement, Vol. 15. Iss. 1. (2020) ISSN: 2153-8999
} 


\section{Introduction}

The Pilipino Cultural Night, or PCN, is the most widely practiced and recognizable tradition for Filipino1 American college student organizations across the United States. If taken at face value, "Pilipino Cultural Night" is relatively ambiguous in nature. However, this term is given a specific meaning and significance within a college environment - one that is simultaneously reflective of students' needs for representation within their campus communities, as well as the finite pathways that are placed before them toward fulfilling these needs. Since the 1970's, the PCN has established itself as an aesthetically recognizable performance genre, but more importantly as a distinct sociocultural experience that is part of the Filipino American culture. An estimated 100,000 college students have participated in PCN performances since their inception, with some singular productions consisting of over 200 cast members with budgets nearing $\$ 30,000$ (Gonzalves, 2009). The scope and magnitude of these annual productions extend beyond the campuses on which they are performed into the families and communities of its performers, who support PCN as audience members, benefactors, and creative consultants.

The salience of the PCN throughout Filipino American communities is extremely notable given a) the PCN's near-exclusivity on university campuses; and b) the relative absence of Filipino Americans from university curricula as well as senior administrative ranks. College students have created their own Filipino American cultural institution within a larger American cultural institution (higher education) where they are largely without systemic power and privilege. In an age where diversity is being touted as a value-added variable to the higher education experience, it is historically under-represented and under-served students, rather than staff and faculty, who are expected to perform significant amounts of the labor that purportedly adds value to the education of all students. This labor is not only uncompensated, but often comes at the additional cost of large amounts of these students' own human and financial capital. The onus on minoritized students to be de facto cultural ambassadors delegitimizes the critical expertise that is needed to beget transformative learning outcomes from diverse student bodies, as well as the diverse pool of staff, faculty, and administrators who actually do possess this expertise. Students are thus left with the ultimatum to represent their cultures and identities to the best of their ability with their often disjointed and self-taught knowledge, or risk having another entity with even less expertise attempt the same - or even worse yet, no one at all. Under these conditions, Filipino American students and their communities have elevated PCN to the status of a cultural cornerstone that attempts to represent the consciousness of Filipino American youth. While far from perfect, the PCN is Filipino American students' most visible platform to make any sort of definitive statement about their hybrid identities that are neither wholly Filipino nor American.

In this study, I explore the motivations of Filipino American students to produce and uphold the tradition of the PCN. Although the production itself derives its name and aesthetic format from the traditional arts of the Philippines, it reflects a particular set of cultural norms that are unique to the Filipino American college student experience. With these contexts of the PCN and higher education environments in mind, this research explores the following questions:

1. How do Filipino Americans understand and reproduce the value of their ethnic identities within a higher education environment?

2. How do higher education institutions actively influence the acceptable contours of racial and ethnic identities? 
As productions with large amounts of human and financial capital invested into them, PCN's are often evaluated on very capitalist terms - whether or not the production achieved its stated goal of portraying some authentic version of Filipino/American culture, and whether or not the expenditures consumed for the sake of these portrayals were ultimately justifiable. Through the narratives of its most involved student leaders, I will illustrate that PCN's true value is more completely understood through the arena it provides to students to combat their invisibility within educational environments. The on-stage product is only one element of a holistic cultural experience that is uniquely Filipino American.

\section{Literature Review}

The PCN is rooted in Filipino American college student movements that emerged during the U.S. Civil Rights era. While Filipino American student organizations existed in U.S. colleges and universities since the early 1900's (Mabalon, 2013), student-led cultural productions that emerged throughout the 1960's-70's were distinct in that students' motives for organizing and performing were a direct manifestation of their progressive reform demands as students of color. Throughout the 1980's until the present, as the Filipino American student population has grown and the sociopolitical contexts of higher education institutions have shifted, the underlying purpose of PCN is perennially up for debate; the political origins of Filipino American student groups are placed at odds with the current demands of many PCN productions that rely on heavy amounts of financial and human capital to produce a commodified, annual performance for a mass audience.

\section{Political Roots and Performative Growth}

Filipino American student organizations who were early adapters of the PCN include the University of California Berkeley's Pilipino American Alliance (1977), UCLA's Samahang Pilipino (1978), and San Francisco State University's Pilipino American Collegiate Endeavor, who is credited as establishing the first PCN in 1973 (Pilipino American Collegiate Endeavor, n.d.). The PCN is aesthetically identified by the combination of four performance elements: first, traditional Filipino dance drawn from the repertoire popularized by the Bayanihan Philippine Dance Company (Gonzalves, 2009); second, music, in the form of instrumental arrangements that accompany traditional dance, as well as choral, individual, or small group singers who perform in Tagalog and English; third, dramatic theater that addresses Filipino/American experiences; and fourth, contemporary American dance forms, such as hip hop, swing, and/or cha cha, which gained popularity amongst cohorts of Filipino American youth throughout history (Mabalon, 2013; Villegas, Kandi, \& Labrador, 2013). While the PCN is a uniquely formatted variety show that combines all of these aspects into one production, the inclusion of traditional Filipino dance is what outwardly signifies the titular cultural component of this event. Whereas contemporary dancing, singing, and acting are known to be part of student-run events throughout the school year such as open mic nights and talent shows, the PCN is the specific annual forum where Filipino dance is placed at the forefront.

PCN performances originated in the 1970's, expanded in scope and magnitude throughout the 1980's-90's to incorporate more artistic elements, and in the late 1990's-2000's have branched out to community colleges and high schools as a result of growing student populations and institutional resources. The common denominator remains that, beyond the performance, $\mathrm{PCN}$ is seen as a rite of passage for Filipino American students to embody their cultural identities in ways 
that are not possible at any other time in their lives. $\mathrm{PCN}$ is an extra-curricular experience to college life that helps students process the inherent questions about their identity and purpose in early adulthood (Gonzalves, 2009; Tiongson, 2006). While significant, these linkages with coming of age, as well as the human and financial resources made available to students exclusively through their universities, also pigeonhole PCN into this particular time period and deem PCN's underlying cultural explorations as irrelevant to other realms of Filipino American life. Cultural theorist Theodore Gonzalves, who participated in PCN's in the 1990's, described the unspoken bonds amongst PCN performers, as well as its evolving and multiple purposes:

It felt like a nice substitute for politics, because it was a way to think of collective action and feel a sense of collective purpose that we were all in the room for the same thing. I guess, in the absence of a political movement or a moment, it feels like the closest thing possible, the next best thing ... You're there for a collective purpose. There's an energy and a spirit behind it ... The PCN was such an interesting experience because it relies on hundreds of folks to make it happen. It requires a lot of time. You celebrate the labor of that. You celebrate the friendship of that (Tiongson, pp. 115-116).

Gonzalves' described "absence of a political movement" refers to the political divides that emerged in the late $20^{\text {th }}$ century as Americans (particularly liberals) re-evaluated their positionality within a diversifying and integrating nation. Filipino American student groups that emerged during the Civil Rights Era - along with other student-of-color groups more broadly - saw their presence in the university as inherently radical. Higher education was viewed as an opportunity to obtain the upward mobility that was denied to minority populations throughout history. Most notable for Filipino Americans was their participation in the Third World Liberation Front-led student strike at San Francisco State College in 1968, which established the first College of Ethnic Studies in the country (Ferguson, 2012; Louie \& Omatsu, 2001; Umemoto, 1989).

As children from the post-1965 immigration wave came of college-going age in the late 1980's and early 1990's, Filipino American organizations sprouted at more universities. Established groups saw large booms in their membership, with some swelling to hundreds of members in any given year. These growths caused differences and divergences in organizational missions and visions, spurring the development of student groups with specialized foci (i.e. political or academic groups versus broadly stated "cultural" groups) and the dissolution of other organizations (Aguilar-San Juan, 1999). Concurrently, the dawn of neoliberal policies during the Reagan era of the 1980's also began to stifle notions of racial and ethnic diversity (both inter- and intra-) in lieu of multiculturalist policies that viewed diversity through a normative lens of Whiteness. Culture became viewed by institutions of power as culturally-based objective differences rather than the social, political, and economic inequities that were significantly influenced by systemic power differentials (Ferguson, 2012). The end result was the stifling of political action and shifting of priorities by Filipino American student organizations, some of whom no longer saw their presence on campus as inherently and necessarily political. Programming sponsored by these groups, who were amongst the largest on their campuses, began to portray the Filipino American culture in a manner that paid homage to a romanticized history that was devoid of the politicized origins of Filipino American community organizing. To that end, PCN because a primary tool of portraying this modern interpretation of the Filipino American identity. 
Rodriguez's Suspended Apocalypse (2010) recounts an incident at the University of California, Berkeley in 2000 that exemplified the tensions between contemporary PCN and the political roots of the production. Student protestors occupied a class building to advocate for affirmative action, while a PCN rehearsal attempted to proceed as normal just outside the building. Rodriguez recounted the irony of a once-radical PCN platform overlooking a tense political action:

Student-performers were simultaneously inventing, rehearsing, and assimilating an eager (if stridently amateurish) production of the Filipino American real ... The students' movements mocked the very historical moment in which their rabid fabrications of Filipino American "history" and "community," and their sincere though no less flimsy counterfeiting of a native homeland, had become a collective gesture of allegiance to a repressive, deeply racist university apparatus: California had passed the paradigmatic Proposition 209 less than three years earlier, rendering affirmative action illegal. (p. 14)

The Pilipino American Alliance (PAA) is one of the oldest Filipino American student organizations in California and was instrumental in organizing students of color at UC Berkeley during the Civil Rights Era (Pilipino American Alliance, n.d.). However, Rodriguez's account of this protest and his critique of PAA members refusing to participate in lieu of their impending PCN, highlight the contradictions that underlie the Filipino American identity within the modern university. PAA, an active advocate for students of color in the Civil Rights Era, was forgoing participation in an affirmative action demonstration three decades later in favor of an annual performance that celebrated a now de-politicized Filipino American identity. Taken within the historical context of the UC Berkeley campus, this incident illustrates how racial/ethnic identities and meanings can shift drastically within college environments over a relatively short period, and simultaneously demonstrates the influence of Filipino American cultural organizations in controlling the narrative of the Filipino American identity to a larger campus community. The UC Berkeley campus currently contains 8 Filipino American organizations (Sabalburo, 2018), but PAA, as the oldest and the largest, is bestowed the privilege of being the flagship organization. The power that comes with this privilege continues to be invaluable in the modern era, even on campuses such as University of California schools that enroll majority-minority student bodies and host multiple resources for students of color. Through PAA's holistic behavior surrounding its PCN - not merely what they produce on stage but also how they place PCN on a pedestal amidst a full calendar of extra-curricular activities - they exhibit how the value and utility of PCN's have changed for the students who participate in them, as well as the campuses on which they are performed. Whereas the intent of PCN has historically been to present a united Filipino American community to a wider audience, its impact can also highlight the philosophical and cultural divides within the community.

\section{The Pilipino Cultural Night as Cultural Capital}

The PCN is a capitalist product in the traditional, economic sense. The performance is funded in the tens of thousands of dollars, derived from a combination of university resources and private fundraising by the performers. It also generates revenue through ticket and advertising sales. But additionally, the PCN also holds great value through its cultural capital. The reason why PCN's across the country are able to attract thousands of young performers every year who have no 
experience in the performing arts (let alone traditional Filipino performing arts) is because the performance holds so much more long-term value in the months-long experience, rather than the mere act of performing in and of itself. The show markets itself as a crucial coming-of-age experience for young Filipino Americans-one that students yearn for but often lack the critical language to describe the source of this hunger. Theodore Gonzalves explains how the length and format of PCN are reflective of the cultural yearnings of Filipino Americans:

"Why are these cultural nights so long, why are they six hours on some campuses?" There's more going on than simply entertainment. It is an engagement with Filipino culture ... It's a specific and unique form through which Filipino Americans are attempting to do it either because of the generational silence of their parents, or because of dominant culture's distortion or omission ... The silence concerning culture creates this hunger ... That's the reason cultural nights tend to last so long: if it's not presented on that night, it won't ever be presented. It means there's no room to tell other stories later on or other venues outside of this (Tiongson, pp. 117118).

In capitalist terms, the PCN's value lies within its rarity. It is a unique (and often lone) opportunity for Filipino Americans to make a collective statement about their culture within a higher education environment. Both the statement itself, and the ability to collectively author it, are rarities for Filipino Americans due to what Gonzalves cites as "generational silence" (elders" unwillingness to discuss Filipino culture) and Filipino Americans" "distortion and omission" (stories told by outsiders, or not at all) from American culture more broadly. This rarity also justifies the economic expenditures that are invested into the production, a majority of which are derived from large university accounts for funding student-initiated programs. With a lack of other programming or course curricula to address the Filipino American experience, PCN is embraced by campus communities as the sole method of empowering this student population. However, the evolving nature of higher education leads to the value of PCN being miscalculated, including by those who earnestly seek to understand this cultural phenomenon more deeply. Although it is experienced by its audience primarily as a theatrical production with cultural and educational components, the outcomes of PCN go beyond artistic merit or educational touchstones. PCN participants embrace its value on a different scale that encapsulates PCN's unique contributions to the university climate. The reputation of PCN in the modern era precedes the PCN performance and reproduces its value in perpetuity for subsequent generations of Filipino American students. Students are not merely invited to be part of a performance, but a cultural experience. What once became a tradition because it was valuable, now remains valuable because it is a tradition.

The shifting priorities of PCN participants over time reflects the fluidity of cultural value. A singular product or experience can have differing value across time and across different populations. As a critique of perceived value and utility, Yosso (2005) challenges the singular construct of cultural capital through the concept of community cultural wealth. Rather than focusing on a hegemonic ideology of capital that normalizes White, middle class values, Yosso illustrates the various ways that marginalized communities utilize the emotional, cognitive, and sociopolitical knowledge acquired through their experiences in the margins of the dominant culture. These forms of aspirational, linguistic, familial, social, navigational, and resistant capital reflect the true readiness of under-served communities to challenge the systems that they are placed into, and their resilience to the perpetual devaluing of their experiences. Yosso emphasizes that 
"Communities of Color are places with multiple strengths," and "the main goals of identifying and documenting cultural wealth are to transform education and empower People of Color to utilize assets already abundant in their communities" (p. 82).

Traditionally speaking, extra-curricular spaces for Filipino Americans and many other under-represented and under-served student demographics have served as arenas for these students to corral their non-traditional cultural capital in order to cope with, resist, and persist in predominantly White institutions (Harper \& Quaye, 2007; Museus, 2008). Non-traditional as they were, these forms of cultural capital nonetheless aspired towards traditionally capitalist means completion of a degree that cost thousands of dollars, ascendance into previously uninhabited socioeconomic tiers, etc. This struggle is tantamount to the experience of minoritized students, who consciously resist the institutions and call for their transformation while simultaneously existing within them. Filipino American student organizations, once seen as a means to achieve greater ends, have grown in size and become incorporated into the campus culture at some universities to the point where they are now institutions unto themselves. The self-sustaining successes of Filipino American student groups within higher education environments are now the ends in and of themselves, rather than a means to achieve outcomes beyond the higher education environment. Consequently, the processes through which students conceive their agency and the value of the Filipino American identity within their organizations illustrate how various scales of community cultural wealth are uniquely in dialogue with one another within the confines of higher education.

With these historical and contemporary contexts of the PCN in mind, an intersectional analysis is necessary to understand the value of the PCN within higher education institutions and Filipino American communities. Like the Filipino American student organizations themselves, the mere presence of a PCN was once seen as a radical moment on a university campus - the opportunity for students who were consciously omitted from the curriculum to write and teach it themselves. While cultural critics such as Gonzalves and Rodriguez argue that PCN has lost some of its cultural value due to its loss of political action, the lens of community cultural wealth from Yosso provides new opportunities to view PCN as a source to understand the knowledge that Filipino American youth utilize to transform higher education. Ultimately, PCN is neither wholly apolitical nor radical. Particularly in a fleeting environment like higher education, individual and collective sensibilities can be engrained as canonical in a short period of time, and can conversely be washed away just as quickly as if they had never existed; actions of resistance can shift into complacent apathy, or vice versa. Thus, those who critique and work with students who espouse these cultural values cannot truly serve these students' needs without a holistic understanding of the contexts within which their Filipino American identities lie.

\section{Methodology}

\section{Research Subjects and Methods}

This study consisted of one-on-one, semi-structured interviews of Filipino American students who participated in PCN, and observations of student organizational meetings. Eleven subjects participated in one-on-one interviews that were conducted in person and audio recorded. Each of the subjects interviewed for this study were purposively recruited from a targeted subject group of people who have held leadership positions for Kapatid, ${ }^{2}$ the Filipino American student organization at Western State University (WSU; pseudonym). Subject pool was a mix of both 
current WSU students and alumni. Interview questions focused on subjects' trajectory through the PCN process - how they got involved in PCN generally, why they became involved as student leaders, and how they reflected back on these experiences at the time of the interview.

In addition to the interviews, I also observed Kapatid board member meetings. These observations were used to compare individual narratives to the organization's collective actions in logistically and creatively supporting the PCN event. During these meetings, I paid close attention to how PCN was addressed by Kapatid leadership relative to the organization more broadly. These points of discussion framed PCN in terms of its logistical (behind-the-scenes) and creative (onstage) components.

\section{Sites of Study}

Western State University is part of the nine-campus University of California (UC) system. WSU enrolled between 1,500-1,800 Filipino Americans from 2006-2016, the decade immediately leading up to the research period (University of California Office of the President, n.d.). Kapatid is one of the largest Filipino American student organizations in the country, with approximately 300-400 members annually. Established in 1974, Kapatid is the oldest and largest of six Filipino American student groups at WSU. Kapatid has been producing an annual PCN since 1980, one of the oldest in the U.S.

\section{Researcher Positionality}

My positionality relative to this research project is a very close and oftentimes overlapping one. I am an alumnus of Kapatid at WSU, having held multiple leadership positions in the organization. Knowing so much about the inner workings of Kapatid, I utilized a constructionist approach to consider the myriad of relevant contexts to subjects' narratives and thus explore the deeper meaning behind them (Esin, Fathi, \& Squire, 2014). As students, Filipino Americans, and organizational leaders, these subjects occupy multiple and intersectional identities and perspectives that influence the ways that they recount their realities for an audience. My positionality lent itself to creating dialogue that enhanced certain subject narratives that may have appeared to be tangential or insignificant to outsiders. My ability to ask questions that only an insider to Kapatid would consider significant, but are nonetheless integral to understanding the reasoning that guides subjects' creative decisions and identity formation, is an invaluable element that is missing from educational research on students of color. For although diverse student populations are on the rise, there is yet to be an equally proportional rise in faculty, staff, and administration who can actively address diverse students' needs and concerns on their own terms (Maramba \& Nadal, 2013; Wang \& Teranishi, 2012).

\section{Findings}

A review of the literature on Filipino American student groups frames their current positioning at a crossroads between their radical political roots and current higher education contexts where they exist as a principal voice for Filipino American culture within the institution rather than explicitly oppositional to it. The PCN, a performative statement about Filipino American culture both on and off stage, exemplifies these tensions. Conversations with and observations of the Kapatid organization illustrate each form of community cultural wealth, providing new ways of 
understanding the value of PCN for students in the modern higher education landscape. Not only do these student leaders exhibit the various scales of value within each type of cultural capital, but the interplay between these various forms also illustrates the engrained struggles of Filipino Americans between their short- and long-term goals, intrinsic and extrinsic rewards, and Filipino and Filipino American cultural traditions. Beyond any singular historical fact or ethnic tradition, it is within these struggles where the true culture of PCN lies.

\section{Resistant Capital}

Resistant capital is the knowledge and skills that are developed through resistance to subordination. This capital has many material forms, such as acts of sociopolitical resistance, to the engrained self-valuing and self-efficacy within communities who are constantly de-valued and de-humanized (Delgado Bernal, 2001; Solorzano \& Delgado Bernal, 2001). Early forms of resistant capital amongst Asian Americans are exemplified through the landmark court decisions that redefined race and ethnicity in the U.S. Cases such as United States v. Wong Kim Ark (1898), Tape v. Hurley (1885), and Korematsu v. United States (1944) all questioned the exclusion of Asians from the sociopolitical fabric of the U.S. In each of these cases, Asian Americans' perspectives developed through oppression gave them the knowledge to challenge the enforcement of public policies as incongruent with the letter of the law and the philosophical principles of the U.S.

The desire to represent Filipino American culture as an appropriate subject of discussion in higher education gives value to the PCN's resistant capital. Unable to see positive images of Filipino Americans on campus or in most mass media outlets, students take the PCN stage as their venue to express the positivity they associate with their culture and their very being. Rather than waiting on institutions to change, students used their own self-determined principles to create representations of their culture within the campus community. However, without acknowledging institutional culpability, marginalized people bear a burden that can counter-productively absolve their institutions of creating change. Currently, the PCN environment reflects the juggling value of resistant capital through the shifting boundaries of the status quo.

Derrick, a former vice president of Kapatid, describes the resistant capital of PCN through the example of cultural knowledge:

PCN is so amazing. It's for everyone - the members who have never been exposed to our organization, to come and be a part of it. $\mathrm{PCN}$ is the performance of what we know to be Filipino culture to us. We want them [cast members] to know a little something more than they did before ... Even something small as that one has Muslim influence or that one has Chinese influence- something more that they didn't know before.

Through this reflection on the purpose of PCN, Derrick refers to the heterogeneity of the Filipino culture that is often ignored by academic institutions and even Filipino/American communities. His last sentence implies the foundational assumption that their audience is largely unaware of the broad culture of the Philippines. Thus, being able to gain a position that allows Filipino American students to challenge the dominant perception of Filipino culture within their university environment is a form of resistance. Based on the growing participation in and attendance of Kapatid's annual PCN performance at Western State University over the last four decades, this act of resistance continues to be extremely valuable to Filipino Americans throughout 
the community. But when the knowledge espoused on the PCN stage is considered within the nowestablished tropes of a PCN genre, the perspective on what actions are resistant, and resistant to which structures, changes drastically.

The PCN performance is anchored by the traditional Filipino dance library - a catalog that portrays the cultures of five distinct ethnolinguistic regions of the Philippines. Although knowledge about these distinct groups - particularly those that are indigenous, pre-colonial groups - is sparse in both Filipino and American educational systems (if not entirely absent), using dance as a means to conduct a brief overview of the breadth of ethnic diversity in the Philippines is the status quo for PCN performers. JD, a former PCN dance coordinator, believes that the normalization of Filipino dance has erased its meaning.

I never got a sense for them-the PCN coordinators, emphasizing why PCN is being done. I think everyone just thinks, let's do a bunch of dances, and show off for our friends and stuff. But they never really emphasize why we should be doing it.

When every PCN that these students are exposed to-whether as participants at WSU or audience members at other schools - contains traditional Filipino dance, the resistant value of Filipino dance decreases as Filipino Americans simply understand it to be a standardized element of the PCN genre. However, the standardization of Filipino dance has bestowed increased cultural capital value upon PCN's dramatic component, known internally at WSU as "Skit." Despite following the same artistic medium of drama every year, PCN Skit's creative direction has the potential to change drastically from year to year, thus drawing the attention of Kapatid membership and audiences alike.

\section{Linguistic Capital}

Linguistic capital is the intellectual and social skills acquired through communication in multiple languages and/or styles. Therefore, it does not only refer to multiple language proficiencies in the traditional sense of separate languages, but also to the ways that people are able to code switch, affect tone, or create hybrid vernaculars that reflect shared understandings in particular settings (Faulstich Orellana et al., 2003; Yosso, 2005). Throughout the global diaspora, Filipinos have often gained upward socioeconomic and cultural mobility due to their English language proficiency and familiarity with Western cultures, all the while maintaining community and family structures through their shared culture and identities.

Within the PCN environment, the one word that reflects the most divergent amounts of linguistic capital for those who wield it is "political." Throughout my interviews with and observations of the Kapatid organization, this term was extremely polarizing and given deep consideration by those who wanted to embrace it and distance themselves from it alike. The term "political" specifically refers to issues of social injustice and inequity, typically related to race and ethnicity, but Kapatid programs have also touched upon issues of gender, sexuality, and imperialism. However, contrary to how the term is used in a civic engagement setting, political debates within Kapatid rarely, if ever, escalate to discussions of affecting change through campaigning for elected officials or influencing public policy, instead remaining as descriptors of isolated incidents or individual agendas. 
When the script for the PCN Skit is written, a common discussion point amongst Kapatid membership is how political the content will lean, and more specifically whether the amount of political content is representative of collective sensibilities amongst Kapatid and thus appropriate for a PCN audience. These three former PCN scriptwriters illustrate the various ways that the term "political" is leveraged in the PCN environment:

Bea (Class of 2002): Our alumni, I wanted them to come back and enjoy a good, funny show. We came in during the era of comedy, so I wanted something that would make our alumni proud. We wanted to make sure it was nice and short, nothing super super serious. People didn’t want anything too political.

Bernie (Class of 2005): I think they [Kapatid members] liked my PCN. It was funny and hard hitting, but they knew that was going to happen. They knew I wasn't going to be about roses and daisies. So when PCN came out and there were some intense scenes, I think they expected that. They knew what type of person I was, so they knew I was going to focus on political issues. Some people liked that, but for those who didn't, at least they were exposed to it.

Jason (Class of 2008): Working with such tough issues as homosexuality and being accepted, within a more conservative school like UCI, we received a lot of backlash. A lot of people didn't like that because it was too serious and the show should be light hearted ... It was a power struggle to gain respect. People were asking, "Who's this guy? What does he know?" I had only been a dance coordinator before. No one associated me with anything political.

Political is one of the five pillars of the Filipino American experience promoted in Kapatid's mission statement, along with academic, community, cultural, and social. But within PCN, which creates Kapatid's largest collective statement in front of a singular audience, the political aspects of the Filipino American experience can become a deal breaker that is instantly incongruous with the lived values of the organization's membership. The three student leaders highlighted above-Bea, Bernie, and Jason, assumed their leadership roles three years apart, significantly illustrating an ebb and flow of the tone of PCN over generations of college students. Bea begins by describing an "era of comedy" in the early 2000's, which shifted past "roses and daisies" with Bernie in the mid 2000's. Thus, Bea and Bernie's respective individual philosophies on political content were congruent with what other senior leaders of Kapatid were expecting from them as writers. But for Jason, by the time he assumed his position in the late 2000's, the pendulum swung back toward a non-political direction, placing him up against resistance from PCN cast members and Kapatid's senior leadership.

The connection between student leaders and the political aspects of their organization are a continuation of Rodriguez's critique of the Pilipino American Alliance at UC Berkeley. The term political, in a counter-intuitive way, is seen as a singular, personal pursuit in the PCN environment. The direct relevance of politics to Filipino/American culture is perennially up for debate, leading to divergent experiences for student leaders based on their support systems and how they can be labeled by others in positions of influence in Kapatid. Bea, Bernie, and Jason all make references to various interest groups - alumni, general members, and an ambiguous, passively stated consensus (e.g. "they," "people") — that influence Kapatid. Therefore, these perspectives not only 
shed light on the linguistic capital value scales of the term political, but also how the language of the Kapatid environment expands traditional definitions of leadership and influence within a higher education environment.

\section{Familial Capital}

Familial capital describes the knowledge and empowerment that are developed amongst kin (Delgado Bernal, 2002). More specifically, marginalized communities develop and sustain familial capital through their expanded networks of family and community members, who connect to one another with the same sense of interdependency and obligation as a nuclear unit. The value of familial capital thus lies in a group's sense of collaboration and their desire to re-define roles in society that have traditionally delineated labor in a rigid fashion.

Although Kapatid members mostly share no biological relations to one another, they constantly refer to one another in Tagalog familial terms such as ate (older sister), kuya (older brother), or ading (younger sibling). This cultural practice of addressing extended family and community members by nuclear family terms is common in Filipino/American culture. The distinction of these titles reflects the ways that Filipino communities have historically depended on one another in environments where they had no other means of coping and resilience. Because of the multiple ways that Kapatid members help one another through the higher education experience, the titles of ate and kuya can add significant value to the cultural wealth of student leadership in the organization.

In addition to artistic and extra-curricular aspirations, a group of informants described their entry into PCN-related leadership positions as a response to collective necessity. Simply put, their presence was needed in order for there to be a PCN. This burden particularly impacted senior Kapatid students and young alumni. Of the eleven student leaders interviewed, three held leadership positions as $4^{\text {th }}$ year students, three as $5^{\text {th }}$ year students, and three as alumni. Bernie became the PCN scriptwriter in his $4^{\text {th }}$ year at WSU, sharing the title with a co-coordinator who was a $5^{\text {th }}$ year senior. He stated, "I applied because honestly, it was expected because I had done PCN for so long. Leadership is hard to come by because people realize it's difficult." This difficulty that Bernie refers to is not simply the extra-curricular time commitments needed to attend meetings, run rehearsals, and to write and develop a script, but also the gravitas to shoulder the emotional burden of holding a highly visible and scrutinized leadership position.

Recognizing the maturity and experience that is required to thrive in a leadership position, Kapatid opens up positions on its board for alumni and $5^{\text {th }}$ year seniors (some of whom graduate early in the year and are no longer students by PCN in the Spring Quarter). This stance differs significantly from the requirements of the organization's executive board, who are all required to be full-time WSU students for the entire academic year. Frank and Bea are two leaders who obtained PCN leadership positions as alumni. "There was a need for a writer that year," stated Frank. "The PCN Coordinators came up to me and said that no one had applied; they were desperate." However, despite such desperation, Bea also admitted that after being a part of PCN for multiple years, she was nonetheless willing to take the job with a sense of satisfaction. "PCN meant a lot to me, so I wanted to give back to the club," she added.

The ascension of elder members of Kapatid into principal leadership positions illustrates that the value of familial capital within Kapatid has grown as the organization's size and scope have grown throughout its existence. While it began as a small, informal student group in the 1970 's, the group now fills over fifty leadership positions annually. These include executive board 
members, PCN-focused leadership, and interns. Within such a nuanced organizational web, elders are expected to take leadership roles, especially since many positions are not open to first-year members. Recent alumni (1-2 years post-graduation) have also held leadership positions throughout the 2000's, coinciding with the organization's largest growths in membership and most expansive developments in programmatic offerings.

The involvement of alumni with their alma maters and former student organizations is common throughout higher education. Alumni from many types of student organizations and higher education institutions form professional associations that serve as mentors and benefactors to current students. However, Kapatid's direct, day-to-day involvement of alumni as part of its core leadership reflects an investment of familial capital that is unique to their organization. Kapatid recognizes that the fulfillment of the goals of an organization with hundreds of members requires extensive human resources that can often not be confined to leaders' time as students. They have changed the dynamics of the higher education community by instilling their alumni as mentors and leaders within a campus that still lacks diverse, skilled leadership at an institutional level in spite of large gains in diverse student populations. Alumni's willingness to remain within the organization, in addition to the organization's continued need for diverse and experienced leaders, exhibits the core foundations and value of familial capital amongst under-served communities.

\section{Social Capital}

Social capital encompasses networks of people and resources that provide support to one another. Oftentimes, social capital obtains value by breaking down de facto barriers that inequitably segregate populations in the margins. Communities find strength in helping one another acculturate to an environment that is unfamiliar at best and antagonistic at worst (Stanton-Salazar, 2001). For Filipino Americans, social capital in an educational environment has enhanced recruitment and retention of students whose immigrant parents are largely unfamiliar with the modern landscape of university systems (Buenavista, 2013). Within Kapatid, however, students' actions demonstrate that the larger environment within which they seek belonging is not the university itself, but the population of their Filipino American peers. Due to the extreme size of the Filipino American student body (1,000+) and Kapatid itself (300-400), students can find pockets of the community to be incongruent with their interests. If not for PCN, these undesirable aspects would put them off from the Filipino American community altogether. Jan described her use of PCN as a refuge:

Last year, the general member retention was pretty bad. It was because Kapatid felt kind of exclusive. Last year, the only reason I really stayed was because of my friends in PCN I definitely can see why people didn't join because the freshmen, they were so cliquey. You would try to talk to them but they would tell us they don't wanna talk to us ... That's why some people don't come out anymore, because people were so exclusive and just tried to stay in their clique.

Although the club is seemingly open and inclusive to all, Jan describes the unspoken barriers and social norms have prevented some students from joining Kapatid. The smaller community that Jan found for herself within PCN helped her move around those barriers and maintain a presence within the Filipino American community. Yet she also acknowledges that others were not as fortunate to have that same support system, thus emphasizing the value of PCN 
as a resource of social capital. Laura, a PCN co-Coordinator at the time of our interview, agreed that PCN was as a sanctuary away from Kapatid, ironically even for its most involved student leaders. She recalled turning to PCN leadership opportunities because of personal conflicts with Kapatid executive board members:

Coming into my 3rd year, there was a whole thing about who was going to be on [Kapatid] Board that year ... I did not want to be on that board with those people. I had a lot of fun being on PCN Board to the point where I was like, I'm just going to continue and stick with PCN Board.

The establishment of PCN as a counter-cultural space for Filipino Americans exhibits the new realities at WSU that challenge the notion of a Filipino American monoculture. It is a common practice for students to list Kapatid and PCN as separate extra-curricular involvements on their résumés and social media profiles, illustrating the shared understanding that while on paper, the existence of PCN depends on Kapatid, the two can be experienced as categorically separate entities. Whereas most literature on under-served students or students of color compares the experiences of these populations to that of the normative majority-White, heterosexual, cisgender, and/or male - the Kapatid environment illustrates a struggle against the majority that is absent of a White population. Filipino American students see the Filipino American community d a normative mainstream, and utilize the social capital they gain through PCN to cope with the aspects of this larger community that they find to be difficult and unwanted. Despite the perceived ideological separation between PCN and Kapatid writ large, student leaders make their community presence felt through the PCN performance-something that may not have happened if they did not have their closer, intimate group to help them cope with the other stressors of the Kapatid experience.

\section{Aspirational Capital}

Aspirational capital is defined as the ability to maintain a positive outlook towards one's future, particularly in the lieu of interpersonal and institutional barriers (Solorzano, 1992). Aspirations are often in dialogue with expectations, defined an outlook on one's future that is grounded within their tangible, material circumstances (Espiritu \& Wolf, 2001). Aspirational capital is thus given value through the resilience of marginalized people to challenge perceptions of what is realistic and plausible; to be able to envision congruence between aspirations and expectations in the face of structural barriers and a dearth of support.

The PCN at Western State University represents Filipino American students' aspirations to see themselves represented in the mainstream campus fabric in ways that are unprecedented in almost every other facet of American higher education. Despite their significant quantitative presence at WSU, Filipino American students remain largely invisible from the campus's predominant popular avenues for student exposure, such as sports, student government, or the performing arts (theater, choir, marching band, etc.). Wesley's description of PCN illustrates how the performance creates an ideal campus presence for students to aspire to:

I wanted to join Kapatid to do PCN and meet people. I knew PCN was one of the largest venues to do that, so I was really excited. There was this wonderment about it going into college, knowing that WSU had such a big Filipino cultural 
organization. I was really looking forward to doing Kapatid and specifically PCN. Especially coming out of high school, I knew this was a really good way for me to get more culturally tuned. It was just everything I was hoping to get out of it.

Through this reflection, Wesley describes Kapatid — and more specifically, PCN — as a specific goal for himself in his first year at Western State University. He contrasts his "wonderment" about WSU's "big Filipino cultural organization" with his high school experience, implying that being a part of the WSU community provides him with opportunities to get "culturally tuned" in ways that he may have aspired to, but did not expect prior to entering college. The power of aspirational capital amongst the Filipino American community is also notable in how it spread mostly due to word of mouth during PCN's largest cultural boom period. As someone who began college in 2005, Wesley was largely unaware of what the PCN performance or overall production process consisted of; social media networks, blogs, and YouTube, now used as primary marketing tools and de facto historical archives, were in their infancy. Rather, Wesley's knowledge of the PCN environment was based largely on the efforts of older Kapatid members who "glorified PCN as the biggest event of the year and something that everybody should do," he stated.

Each year that PCN is replicated and grows in stature within the WSU campus community, it increases its value of aspirational capital. Despite the lack of representation of Filipino Americans in prominent aspects of WSU student life, each year, Kapatid independently produces the largest student-run performance at WSU. The stature of the event itself is part the show's mystique and the organization's collective identity. PCN is romanticized in such a way that goes beyond its objective measures of audience attendance (often over 2,000) and performer participation (between 200-300 cast members), which are already exceptional in and of themselves. These aspirations for building on the Filipino American specter are a driving factor for participation in PCN, overcoming the fact that a majority of students have never seen a PCN nor participated in the performing arts before coming to college. As students are attracted into the PCN process and return to the production in subsequent years, their aspirations for improving the performance and their own cultural awareness are also what keeps them motivated to participate despite interpersonal conflicts and their other academic and professional commitments. In essence, PCN becomes a significant part of their college curriculum, something that they now expect to be a part of their higher education experience rather than extraneous to it.

\section{Navigational Capital}

Whereas social capital describes the ability for marginalized communities to utilize their assets to persist and thrive in an abstract sense, navigational capital builds upon social capital by encompassing how resources and knowledge obtained from non-traditional sources allow marginalized communities to survive and thrive toward particular outcomes (Yosso, 2005). To use the term directly, it allows under-represented and under-served communities to follow a set path (navigate) that although seemingly objectively outlined, contains many inequitable barriers to access. As I have discussed previously, such pathways within an educational environment are often framed in completionist terms - matriculation, recruitment, retention, graduation, etc. But within a PCN environment, Filipino American students' navigational capital is unique is that it comes into their possession as a result of being part of the larger higher education environment, yet is 
valued as a means to navigate the self-contained pathways of the Filipino American student community.

Angelica recalled being recruited into PCN as a first-year student, under the premise that the event would be an appropriate starting point for the Filipino American experience at WSU:

They said, "This is what you do as a first year, and it'll open your eyes to what Kapatid has to offer as a whole." ... I had never heard of PCN ever in my life. My ate really pushed me to put myself out there. I didn't know what to expect. I was overwhelmed ... I did it because they recommended it to me, they said it'd be a really great experience, and it ended up being a big part of my college life.

Despite having never heard of PCN coming into college, Angelica participated in five PCN's, obtaining the title of PCN scriptwriter in her final year. She described her role as a scriptwriter as a way to connect with her family and culture in ways that she could not while growing up. "I wanted to write the script because my family, we don't really express our emotions at all," she said. "It was all the words I wanted to say but I couldn't." Angelica's Filipino American experience is characterized through the gateway of Kapatid, and the ultimate goal of PCN as the final actualization of Filipino American cultural awareness. In recounting this trajectory, she is very conscious to note the influence of her ate as the conduit that set her down this path. The elder members of Kapatid utilize their experience to help newer students navigate the seemingly ambiguous pathways presented to them by such a large organization in a large university.

The terminal nature of PCN and the specific value of the navigational capital utilized by Kapatid members during their time as students are also brought to light as interviewees reflect on their lives after college. All subjects indicated that once their involvement with Kapatid was over, so too was their involvement with performing arts and Filipino American community organizations more broadly. "After college, you have to work," stated Mikayla. "Your priorities are toward your family." Frank made a clear distinction between the purpose of performing arts inside and outside of a higher education environment when he stated, "PCN was completely amateur, but considering the forum and venue, it was appropriate. I don't know if anything I can come up with can be used to generate money."

A majority of the subjects stated that they had not seen a PCN (including re-watching their own on video) since they last participated in one. I do not read this hard and fast separation as negative or fleeting in and of itself. Many college alumni are immediately disconnected from their institutions and never go back for a variety of reasons; this separation in and of itself does not reflect the value of the experience. The same is true for the PCN. In having a distinct outcome to aspire to, Kapatid members were able to navigate the complex pathways to achieving this goal and help future cohorts of students along as well, lifting as they climbed. As Angelica stated, her ate, only three years older than her at the time, was able to utilize the significant knowledge she had gained in a short amount of time to help a younger student, all the while still continuing to experience PCN and learn about Filipino American culture alongside Angelica. The value of the navigational capital that Filipino American students use to mentor one another through an almost entirely unfamiliar PCN process exemplifies the value of community networks and the process of cultural awareness as a collective experience rather than an individual pursuit. 


\section{Discussion}

Despite its broad-natured title, the PCN is a statement of how Filipino American students understand their ethnic identities within their particular university setting. At Western State University, home to one of the oldest and largest PCN productions in the country, the PCN experience is now deeply rooted as a central aspect of student life for Filipino Americans. It is not seen as fledgling or fleeting, as many initiatives geared toward minoritized students in higher education often are (including other programs developed by Kapatid outside of PCN). However, it is still seen as a lone, annual forum where Filipino American identities are performed both on stage and behind the scenes. PCN's rarity and reputation thus create an environment that is unlike any other in higher education or in the Filipino American community.

The experiences from within the PCN environment transform the traditional viewpoint of education in that the community cultural wealth that is acquired and reproduced by Kapatid members at Western State University is not for the tangible educational benchmarks that typically belie the education system, such as grades, enrollment, or graduation statistics. Rather, the PCN environment - moreso than the Kapatid or WSU environments that facilitate PCN's existence - is established as the tangible outcome toward which Filipino American students hope to invest their community cultural wealth. It is through understanding the fluctuating values of community cultural wealth that the true culture cited in the very naming of the PCN truly comes to light, beyond the traditional performing arts of these students' ancestral heritage.

The PCN has thrived within the WSU campus because of the institution's exceptionally high concentration of Filipino American students with similar interests and aspirations, combined with the vast financial and logistical resources that support the fulfillment of these students' cultural needs. But these institutional contexts have also created a glass ceiling that has boxed PCN within certain parameters. Since the late 1990's, WSU has enrolled more Filipino American students than its University of California counterparts, yet the Filipino American student leaders who are the most actively involved in their community continue to stay within their own networks for mentorship and advice. Glaringly absent from these students' experiences in PCN itself or Kapatid writ large have been any mentions of WSU's Asian American Studies faculty, Cross Cultural Center student affairs unit, or the vast network of Filipino American community organizations in the surrounding area. This close-knit network reflects a continued disconnect between Filipino American students and WSU, and thus preserves many of Kapatid's artistic and cultural traditions within its own boundaries.

The self-sustaining environment of Kapatid, and more specifically its PCN, demonstrates that concentric circles of diversity and inclusion must be developed in order for universities to thrive as diverse, inclusive, and equitable environments. Student diversity must be supported by inclusion throughout the institution through systems of integration and accountability. It is not merely enough to think of diversity as metrics of educational milestones such as enrollment and graduation. As the Filipino American students of WSU have shown, students have identity-related goals and aspirations that are facilitated by the university environment but independent of their pursuit of a college degree. Therefore, these goals are largely pursued in self-sustaining environments where students operate almost entirely independently from university representatives. In the case of Kapatid at WSU, this disconnect between students and the university is particularly notable given WSU's extensive resources for diverse student populations; yet this is the tangible outcome when faculty, staff, and student diversity are treated as separate realms that are independent of and unaccountable to one another. Until Filipino American students are shown 
by their institutions that there are possibilities beyond PCN that will be intellectually and financially nurtured, they will continue to preserve the status quo within their own spaces.

The Kapatid PCN environment is full of student leaders whose goals are simultaneously short- and long-term. They aspire to produce a performance that will not only be satisfying in the moment, but establish a legacy that will make past cohorts proud and future cohorts can aspire to build upon. Their goals are both intrinsic and extrinsic, to themselves as individuals, the organization, and the campus. As young adults, they seek to validate their identity through performing arts and the embodiment of their culture with other Filipino Americans, and in doing so also seek to legitimize their student organization as a significant influence in the campus community - an entity that contributes to the campus climate much like any other "mainstream" organization such as a Greek letter organization, sports team, or student government. More specifically, their goals are also Filipino and Filipino American. Homage is paid to a mythologized cultural authenticity that has been devalued and stripped away from them in a U.S. context. As many of these student leaders have attested, the generational silence of growing up Filipino American has been normalized for them. It is normalized to the point where they speak of their desire to embody their culture as an innate hunger, without acknowledging that they have been starved. They are so used to never seeing themselves celebrated by their institutions that when an opportunity presents itself to finally stand upon a pedestal, they latch onto it with ferocity. Despite an abundance of resources that exist on their campus, they proceed independently because their educational institutions have always treated them as outsiders. Ultimately, these ways that Filipino American students utilize their community cultural wealth to achieve their goals are the true cultural capital of the PCN.

\section{Notes.}

1. This discrepancy between the usage of "Filipino" and "Pilipino" is part of a larger discussion on semantics and political identity within the Philippine diaspora. The word "Pilipino" is of Tagalog origin—a language that has no "F" sound. This spelling of the word has risen to prominence in the U.S. because of the large population of Tagalog speaking Filipino immigrants. "Filipino," however, is an all-encompassing term, recognizing that there are certain Philippine languages which feature the " $F$ " phoneme, as well as recognizing the influence of Spanish and English on the modern Filipino vernacular. In this paper, I will use "Pilipino" to exclusively refer to proper nouns/entities using this spelling and "Filipino" to address all other entities more broadly.

2. Tagalog for "sibling"; pseudonym

\section{References}

Aguilar-San Juan, K. (1999). The state of Asian America: Activism and resistance in the 1990s. South End Press.

Buenavista, T. (2013). Pilipinos in the middle: Higher education and a sociocultural context of contradiction. In D. Maramba \& R. Bonus (Eds.), The other students: Filipino Americans, education, and power (pp. 259-276). Information Age Publishing. 
Delgado Bernal, D. (2001). Living and learning pedagogies of the home: The mestiza consciousness of Chicana students. International Journal of Qualitative Studies in Education, 14(5), 623-639.

Delgado Bernal, D. (2002). Critical race theory, LatCrit theory and critical raced-gendered epistemologies: recognizing students of color as holders and creators of knowledge, Qualitative Inquiry, 8(1), 105-126.

Esin, C., Fathi, M., \& Squire, C. (2014). Narrative analysis: The constructionist approach. In U. Flick (Ed.), The SAGE handbook of qualitative data analysis (pp. 203-217). Sage.

Espiritu, Y. L., \& Wolf, D. L. (2001). The paradox of assimilation: Children of Filipino immigrants in San Diego. In R. Rumbaut \& A. Portes (Eds.), Ethnicities: Children of immigrants in America (pp. 157-186). University of California Press.

Faulstich Orellana, M., Reynolds, J., Dorner, L., \& Meza, M. (2003). In other words: Translating or "para-phrasing" as a family literary practice in immigrant households. Reading Research Quarterly, 38(1), 12-34.

Ferguson, R. A. (2012). The reorder of things: The university and its pedagogies of minority difference. University of Minnesota Press.

Gonzalves, T. S. (2009). The day the dancers stayed: Performing in the Filipino/American diaspora. Temple University Press.

Harper, S. R., \& Quaye, S. J. (2007). Student organizations as venues for Black identity expression and development among African American male student leaders. Journal of College Student Development, 48(2), 127-144.

Louie, S., \& Omatsu, G. (Eds.). (2001). Asian Americans: The movement and the moment. Asian American Studies Center.

Mabalon, D. B. (2013). Little manila is in the heart: The making of the Filipinalo American community in Stockton, California. Duke University Press Books.

Maramba, D. C., \& Nadal, K. (2013). Exploring the Filipino American faculty pipeline: Implications for higher education and Filipino American students. In D. C. Maramba \& R. Bonus (Eds.), The other students: Filipino Americans, education, and power (pp. 297308). Information Age Publishing.

Museus, S. D. (2008). The role of ethnic student organizations in fostering African American and Asian American students' cultural adjustment and membership at predominantly white institutions. Journal of College Student Development, 49(6), 568-586.

Pilipino American Alliance (n.d.). What is Pilipino American Alliance? Retrieved from http://ucbpaa.wixsite.com/ucbpaa.

Pilipino American Collegiate Endeavor (n.d.). What is Pilipino Cultural Night? Retrieved from www.pacesfsu1967.com.

Rodriguez, D. (2010). Suspended apocalypse: White supremacy, genocide, and the Filipino condition. University of Minnesota Press.

Sabalburo, E. (2018). I don't understand what it means to be Filipino: Navigating Pilipinx American history month. Retrieved from http://www.dailycal.org/2018/11/03/i-dontunderstand-what-it-means-to-be-filipino-navigating-pilipinx-american-history-month.

Solorzano, D. (1992). Chicano mobility aspirations: A theoretical and empirical note. Latino Studies Journal, 3, 48-66.

Solorzano, D., \& Delgado Bernal, D. (2001). Critical race theory, transformational resistance and social justice: Chicana and Chicano students in an urban context. Urban Education, 36, 308-342. 
Stanton-Salazar, R. D. (2001). Manufacturing hope and despair: The school and kin support networks of US-Mexican youth. Teachers College Press.

Tiongson, A. T. (2006). On the politics of (Filipino) youth culture. In A. T. Tiongson, E. V. Gutierrez, \& E.V. Gutierrez (Eds.), Positively no Filipinos allowed: Building communities and discourse (pp. 111-123). Temple University Press.

Umemoto, K. (1989). “On strike!” San Francisco state college strike, 1968-69: The role of Asian American students. Amerasia Journal, 15(1), 3-41.

University of California Office of the President. (n.d). Statistical summary of students and staff. Retrieved September 27, 2015, from http://legacy-its.ucop.edu/uwnews/stat/

Villegas, M. R., Kandi, K., \& Labrador, R. N. (Eds.). (2013). Empire of funk: Hip hop and representation in Filipina/o America. Cognella Academic Publishing.

Wang, H., \& Teranishi, R. T. (2012). Asian American and Pacific Islander (AAPI) background and statistics: Perspectives on the representation and inclusion of AAPI faculty, staff, and student affairs professionals. In D. Ching \& A. Agbayani (Eds.), Asian Americans and Pacific Islanders in higher education: Research and perspectives on identity, leadership, and success (pp. 3-28). National Association of Student Personnel Adminisrtators.

Yosso, T. (2005). Whose culture has capital? A critical race theory discussion of community cultural wealth. Race Ethnicity and Education, 8(1), 69-91.

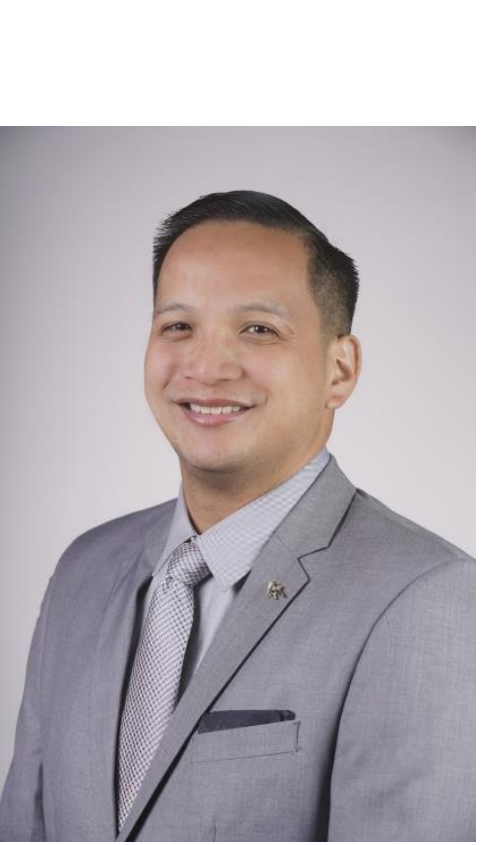

\section{About the Author}

Xavier J. Hernandez, $\mathrm{PhD}$, is the Diversity and Inclusion Program Officer for the College of Health Sciences at the University of California, Irvine. He holds a PhD in Educational Policy Studies with a Graduate Minor in Asian American Studies from the University of Illinois, Urbana-Champaign, as well as an MA in Asian American Studies from San Francisco State University. He has also studied abroad as an undergraduate at the University of the Philippines, Diliman. His academic research and professional work focus on diversity and inclusion efforts in higher education, with multiple projects relating to undergraduate, graduate/professional, staff, and faculty-facing initiatives. Dr. Hernandez has previously been the Director of the Asian American and Asian Resource and Cultural Center at Purdue University. He also has experience as an instructor with the University of Illinois, Urbana-Champaign College of Liberal Arts and the Purdue University Asian American Studies Program, respectively. His academic publications include articles in Race, Ethnicity, \& Education, Journal of Diversity in Higher Education, and the monograph Asian Americans in Higher Education: Charting New Realities, co-authored with Drs. Yoon K. Pak and Dina C. Maramba. 


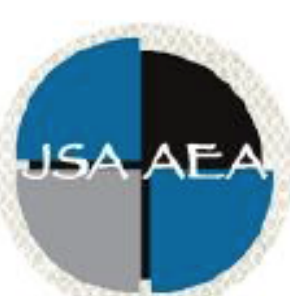

Vol.15 Iss.1 (2020)

\title{
Journal of Southeast Asian American Education and Advancement
}

\author{
Www.JSAAEA.org
}

\section{Editor}

Dr. Wayne E. Wright

Purdue University

Associate Editors

Dr. Chhany Sak-Humphry

University of Hawaii at Manoa

Dr. Phitsamay Sychitkokhong Uy

University of Massachusetts, Lowell

\author{
Book Review Editor \\ Dr. Vichet Chhuon \\ University of Minnesota \\ Creative Works Editor \\ Bryan Thao Worra \\ Lao Assistance Center \\ Journal Manager \\ Fang Gao \\ Purdue University
}

Editorial Review Board

\author{
Dr. Steve Arounsack \\ California State University, Stanislaus \\ Dr. Sovicheth Boun \\ Salem State University \\ Dr. Virak Chan \\ Purdue University \\ Dr. Loan Dao \\ University of Massachusetts Boston
}

\author{
Dr. Carl L. Bankston III \\ Tulane University \\ Dr. Phala Chea \\ Lowell Public Schools \\ Dr. George Chigas \\ University of Massachusetts, Lowell \\ Dr. Hien Duc Do \\ San Jose State University
}




\author{
Dr. Changming Duan \\ University of Missouri-Kansas City \\ Dr. Sothy Eng \\ Lehigh University \\ Dr. Vincent K. Her \\ University of Wisconsin, Eau Claire \\ Dr. Peter Nien-Chu Kiang \\ University of Massachusetts, Boston \\ Dr. Kevin K. Kumashiro \\ University of Illinois, Chicago \\ Dr. Ha Lam \\ Independent Scholar \\ Dr. Jonathan H. X. Lee \\ San Francisco State University \\ Dr. Monirith Ly \\ Royal University of Phnom Penh \\ Dr. Bic Ngo \\ University of Minnesota \\ Dr. Leakhena Nou \\ California State University, Long Beach \\ Dr. Mark Pfeifer \\ SUNY Institute of Technology \\ Dr. Loan T. Phan \\ University of New Hampshire \\ Dr. Karen Quintiliani \\ California State University, Long Beach \\ Dr. Angela Reyes \\ Hunter College \\ The City University of New York \\ Dr. Fay Shin \\ California State University, Long Beach \\ Dr. Christine Su \\ College of San Mateo \\ Dr. Alisia Tran \\ Arizona State University \\ Dr. Khatharya Um \\ University of California, Berkeley \\ Dr. Kim Tran \\ University of California, Los Angeles, \\ Glendale Community College \\ Dr. Molly Wiebie \\ The University of Texas at Austin
}

Dr. Sophal Ear

Occidental College

Dr. Jeremy Hein

University of Wisconsin, Eau Claire

Dr. Nancy H. Hornberger

University of Pennsylvania

Dr. Peter Tan Keo

New York University

Dr. Yvonne Kwan

San Jose State University

Dr. Ravy Lao

California State University, Los Angeles

Dr. Stacey Lee

University of Wisconsin, Madison

Dr. Sue Needham

California State University, Dominguez Hills

Dr. Max Niedzwiecki

Daylight Consulting Group

Dr. Clara Park

California State University, Northridge

Dr. Giang Pham

University of Massachusetts Amherst

Dr. Malaphone Phommasa

University of Clifornia Santa Barbara

Dr. Kalyani Rai

University of Wisconsin-Milwaukee

Dr. Cathy J. Schlund-Vials

University of Connecticut, Storrs

Dr. Nancy J. Smith-Hefner

Boston University

Dr. Yer J. Thao

Portland State University

Dr. Monica M. Trieu

Purdue University

Dr. Silvy Un

Saint Paul Public Schools

Dr. Linda Trinh Vo

University of California, Irvine

Dr. Yang Sao Xiong

The University of Wisconsin-Madison

Dr. Zha Blong Xiong

University of Minnesota 


\section{Doctoral Student Editorial Review Board}

\author{
Linh Dang \\ University of Rochester \\ My-Lan Huynh \\ California State University East Bay \\ Jacqueline Mac \\ Indiana University \\ Hoa Nha Nguyen \\ Boston College \\ Thien-Huong Ninh \\ University of Southern California \\ Latana Thaviseth \\ University of California Los Angeles \\ Mai Vang \\ University of Massachusetts Boston \\ Soua Xiong \\ San Diego State University \\ Claremont Graduate University
}

\author{
Annie BichLoan Duong \\ San Joaquin County Office of Education \\ Vanessa Sovanika Na \\ University of California SanDiego \\ Dung Minh Mao \\ University of Minnesota \\ Khoi Nguyen \\ George Mason University \\ Linda Marie Pheng \\ University of Wisconsin-Madison \\ Krissyvan Truong \\ Claremont Graduate University \\ Melissa Vang \\ San Diego State University
}

